\title{
A DINÂMICA DAS DECISÕES FINANCEIRAS
}

\author{
Alexandre Assaf Neto \\ Professor Doutor da FEA/USP - Ribeirão Preto \\ Consultor de Empresas em Gestão Financeira
}

As decisões financeiras de empresas inseridas em economias em desenvolvimento requerem uma reflexão mais crítica de seus aspectos conflitantes, exigindo uma adaptação a realidade dos negócios.

O processo de tomada de decisões reflete a essência do conceito de Administração. Administrar é decidir, e a continuidade de qualquer negócio depende da qualidade das decisões tomadas por seus administradores nos vários níveis organizacionais. E estas decisões, por sua vez, são tomadas com os dados e as informações viabilizados pela Contabilidade, levantados pelo comportamento do mercado e desempenho interno da empresa.

No entanto, este processo decisorial essencial ao sucesso de toda empresa, vem assumindo complexidade e risco cada vez maiores na economia brasileira. Desequilíbrios nas taxas de juros, desajustes de mercado, ausência de poupança a longo prazo, intervenções freqüentes nas regras da economia, entre outros aspectos, vêm exigindo uma capacidade mais analítica e questionadora das unidades decisórias. Conceitos financeiros consagrados em outros ambientes costumam encontrar enormes dificuldades de adaptação em nossa realidade empresarial, demandando um conjunto de ajustes e reflexões nem sempre seguidos pelo mercado.

Este artigo, basicamente, tem por finalidade discutir as decisões financeiras das empresas no contexto econômico brasileiro, refletindo sobre seus aspectos mais críticos e conflitantes. $\mathrm{O}$ artigo começa com uma avaliação das decisões de investimento e financiamento adotadas convencionalmente pela Administração financeira, promovendo, com esta estrutura padrão, questionamentos e análises concernentes a sua adoção pela empresa nacional.

\section{AS DECISÕES FINANCEIRAS}

Qualquer que seja a natureza de sua atividade operacional, uma empresa á avaliada como tomadora de duas grandes decisões : decisão de investimento - aplicação de recursos - e decisão de financiamento captação de recursos.

Uma terceira decisão, envolvendo a alocação do resultado líquido da empresa, também conhecida por decisão de dividendos, é geralmente incluída na área de financiamento, por representar, em ultima análise, uma alternativa de financiar suas atividades.

Estas decisões são tomadas pelas empresas de forma contínua e inevitável. As decisões de investimento envolvem todo o processo de identificação, avaliação e seleção das alternativas de aplicações de recursos, conforme identificadas nos Ativos. As decisões de financiamento, por seu lado, envolvem a definição da natureza dos fundos aplicados, ou seja, a estrutura das fontes de capital demandadas pelas decisões de investimento.

As duas grandes áreas decisoriais da empresa devem ser apresentadas de maneira bastante integradas entre si. Enquanto as decisões de financiamento descrevem as taxas de retorno exigidas pelos detentores de capital, as oportunidades de investimento centram suas preocupações nos retornos esperados. 
Estabelece-se, em essência, um portfólio de oferta de fundos disponíveis para investimento e outro de alternativas de aplicação de valores, verificando-se uma relação inversa entre a taxa de retorno esperada e o custo de financiamento.

A integração descrita entre as áreas de decisão das empresas ocorre inclusive com a política de dividendos. Uma decisão de reter os lucros para reinvestimento implica, necessariamente, na avaliação de que o retorno gerado pela empresa supera ao ganho que o acionista poderia obter ao dispor de seus lucros. Logo, a reaplicação dos resultados líquidos pela empresa é economicamente melhor justificada quando o retorno prometido pelos negócios superar as taxas oferecidas por outras oportunidades equivalentes de investimento. Neste inter-relacionamento entre as decisões de investimentos e dividendos, é interessante observar que as oportunidades de aplicações de fundos dos investidores (pessoa física) não coincidem com as alternativas de investimento disponíveis às empresas.

Por outro lado, a inter-relação entre as decisões de financiamento e a de distribuição dos lucros se verificada pela opção da empresa em manter maior ou melhor volume de capital próprio financiando seus investimentos. Em verdade, a decisão de dividendos é uma decisão de financiamento mediante capital próprio ao reter resultados, ou capital de terceiros ao distribuir resultados.

Apesar destes aspectos esclarecedores de integração das decisões financeiras, a hipótese adotada de perfeição no mercado de capitais leva a uma separação em seus estudos. Para esta concepção mais teórica das finanças das empresas, assume-se, implicitamente, a idéia de que é permitido aos acionistas manterem uma carteira de ativos representativa da carteira de investimentos decididos pela empresa.

Com relação a este assunto, Modigliani \& Miller ${ }^{1}$ demonstram em seu famoso artigo publicado que a empresa não se valoriza pelo uso, mesmo que bastante sensato, de capital de terceiros. Não existe, em verdade, uma combinação econômica ótima em termos de maximização do valor da empresa, entre capitais próprios e de terceiros, sendo a empresa avaliada prioritariamente com base na qualidade de suas decisões de investimento. Em outras palavras, o valor de uma empresa independe da forma como ela é financiada; sua riqueza é mensurada pela qualidade de seus investimentos, obtida pela relação de equilíbrio entre retorno e risco esperados, não sofrendo penalizações à medida que o endividamento aumenta. Portanto, nenhum ativo pode se tornar mais ou menos atraente, do ponto de vista econômico, como reflexo de uma decisão de financiamento tomada.

Como conseqüência, ainda, a taxa de atratividade da empresa, definida pelo custo de suas fontes de recursos, tem seu percentual estabelecido independente da estrutura de capital apresentada, mantendo-se inalterada em todos os níveis de endividamento. Com isto, as idéias propostas por Modigliani \& Miller descartam a possibilidade da empresa formar uma composição de financiamento tida como ótima, ou seja, aquela estrutura que leva a minimização do custo de capital da empresa e, por conseguinte, à maximização dos resultados de suas aplicações.

Em essência, esta proposição baseia-se na hipótese abordada anteriormente de mercado perfeito, na qual os investidores podem reproduzir a mesma estrutura de capital mantida pela empresa. Todas as alternativas disponíveis a uma empresa também são oferecidas aos seus proprietários, podendo reproduzirem suas decisões.

\footnotetext{
${ }^{1}$ MODIGLIANI, Franco \& MILLER, Merton $\mathrm{H}$. The costo of capital corporate finance and the theory of investiment. In: American Economic Review, jun., 1958.
}

Caderno de Estudos, São Paulo, FIPECAFI, v.16, p.9 25, julho/dezembro 1997 
Logo, o valor de duas empresas absolutamente iguais, exceto na forma como são financiadas, tem que ser o mesmo. Nas empresas mais endividadas e, por conseqüência, com maior risco financeiro, os acionistas são levados a aumentar a taxa de capitalização de suas aplicações, compensando a presença de recursos de terceiros supostamente mais baratos. Em empresas mais capitalizadas, ao contrário, a taxa de capitalização utilizada é menor, como reflexo de um maior nível de segurança, permitindo que a média ponderada entre os fundos próprios e de terceiros permaneça no mesmo patamar de uma empresa endividada.

Desta maneira a linha do custo do capital total da empresa não se altera diante das mudanças na divisão entre capital próprio e de terceiros. O seu valor é constante, sendo formado independentemente do nível de endividamento assumido pela empresa. Alterações, que venham a ocorrer na estrutura de capital não promovem efeitos sobre o valor da empresa, prevalecendo o processo compensatório descrito, envolvendo fundos de terceiros e próprios.

A proposição de Modigliani \& Miller foi empiricamente demonstrada em diversos trabalhos publicados, ressaltando-se sempre a sua importância, em condições próximas ao de mercado perfeito. Diante da reconhecida presença de imperfeições no mercado, vários argumentos surgiram em debate, tornando mais polêmica a questão da independência entre o valor da empresa e sua estrutura de capital. Uma proposição adicional dos autores, sinaliza para a economia de imposto de renda promovida pelas despesas financeiras como a vantagem do uso de capital de terceiros mais baratos.

Esta polêmica de mercado perfeito é bastante acirrada no Brasil, principalmente diante da presença de taxas de juros diferenciadas determinadas pela natureza da fonte de financiamento, e não pelo risco oferecido pela decisão de crédito. Em verdade, não é o risco da operação que a priori define o custo do dinheiro; em grande parte, o encargo financeiro é definido pela natureza do recurso.

Recursos provenientes de agentes oficiais de crédito (sistema BNDES), por exemplo), principal fonte de dinheiro a longo prazo na economia, são oferecidos, em geral, a taxas inferiores às livremente praticadas no mercado. Estas alternativas de financiamento oficial costumam proporcionar, ainda, condições de amortização bastante atraentes, comparadas com outras linhas de crédito, principalmente pelo prazo e carência concedidos.

Nestas condições, determinada decisão de alocação de capital, se rejeitada quando cotejada com as taxas de juros e condições correntes de mercado, pode se apresentar atraente se financiada com recursos oficiais, caracteristicamente subsidiados e de prazos mais longos. De forma, incoerente, para a Teoria de Finanças, em algumas decisões não é a qualidade econômica do investimento que define com exclusividade o valor dos ativos, mas também a forma como ele é financiado, podendo a estrutura de capital selecionada alterar a própria atratividade do investimento ${ }^{2}$.

Este desajuste presente desde a década de 70 , no mercado de capitais brasileiro invalida, ainda, qualquer tentativa de se chegar a uma estrutura de capital definida como ótima, ou seja, aquela composta de recursos que promovem um menor custo médio ponderado de capital e, por conseqüência, uma maximização do resultado. A reta do custo do capital de terceiros, contínua e convencionalmente ascendente em relação ao risco assumido pela empresa, revela-se segmentada diante da natureza da fonte de financiamento. Os recursos podem ser captados a taxas de mercado em encargos subsidiados (recursos oficiais) ou, ainda, com

\footnotetext{
${ }^{2}$ Estas conclusões perduram na economia brasileira há muito tempo. Importantes avaliações originais sobre o assunto podem ser vistas em : ASSAF NETOP, Alexandre \& MARTINS, Eliseu. Administração Financeira. São Paulo: Atlas, 1985.
}

Caderno de Estudos, São Paulo, FIPECAFI, v.16, p.9 25, julho/dezembro 1997 
custos acima dos parâmetros médios de mercado (captações com variação cambial em diversos momentos, leasing, etc).

Logo, é impossível a uma empresa, inserida neste contexto de descontinuidade da linha do capital de terceiros, definir seu nível adequado de endividamento sem o conhecimento prévio dos encargos e condições das fontes selecionadas de financiamento. Os passivos, ainda, costumam ser indexados pelo uso de diferentes taxas e fatores (variação cambial, TJLP, etc.), promovendo alterações relevantes na estrutura de capital e, portanto, no risco financeiro da empresa.

\section{CONCEITO E AVALIACÃO DOS RESULTADOS OPERACIONAIS E A INTERDEPENDÊNCIA} ECONÔMICA DAS DECISÕES

Todo o arcabouço conceitual das decisões financeiras, conforme discutido no item anterior, tem sua avaliação fundamentada pelos resultados operacionais. Através do desempenho econômico do empreendimento, o lucro operacional define os limites de remuneração das fontes de capital da empresa; as decisões de investimento são avaliadas, de maneira incremental, por valores esperados de fluxos de caixa operacionais, e assim por diante.

$\mathrm{O}$ indicador do retorno sobre o total investimento empresarial $(\mathrm{ROI})$ é medido, basicamente, pela relação entre o resultado gerado pelos ativos - interpretado como operacional - e o montante dos investimentos realizados gerador do resultado operacional. Esta medida baseada em resultados provenientes da atividade objeto da empresa, quantifica o retorno produzido pelas decisões de investimento, e permitem que se proceda, pelos valores apurados, a uma avaliação sobre a atividade econômica do empreendimento, definindo inclusive, a atratividade e as condições de sua continuidade.

Por outro lado, o desempenho do ROI sinaliza também as decisões de financiamento, principalmente em relação ao custo de captação (ki). O percentual do ROI deve constituir-se no nível máximo de custo dos passivos empresariais de forma a viabilizar economicamente suas decisões. Empresas com spread desfavorável $(\mathrm{ROI}<\mathrm{ki})$ sacrificam diretamente o retorno de seus proprietários além de promoverem, ao longo do tempo, o próprio desequilíbrio financeiro. Assim, para a tomada de decisão de financiamento de dois fatores devem ser considerados:

(a) econômico, avaliado a partir da relação entre o retorno do investimento e o custo de captação. A agregação do valor econômico em uma empresa e, consequentemente, sua valorização de mercado, se verifica quando o lucro operacional, apurado em um determinado momento, superar o custo total de capital da empresa, e;

(b) financeiro, identificado pela sincronização entre a capacidade de geração de caixa de negócios e a planilha de desembolsos exigidos pelos passivos. O equilíbrio financeiro de uma empresa pressupõe uma interdependência de prazos entre ativos e passivos, ou seja, a maturidade das decisões de investimento deve ser compatíveis no tempo com as decisões de financiamento.

O retorno sobre o patrimônio líquido (RSPL), outro indicador de desempenho, é mensurado diretamente pela relação entre o lucro líquido e o montante do capital próprio utilizado na apuração deste resultado.

Sempre que o RSPL superar ao ROI, denota que a empresa alavanca de modo favorável os resultados de seus proprietários mediante o uso de recursos de terceiros mais baratos em relação ao retorno que 
produzem. Indica, em outras palavras, uma agregação de valor ao retorno dos proprietários medida pelo diferencial positivo entre as taxas de aplicação e captação. Empresas que apuram um ROI maior que o RSPL revelam, por outro lado, uma estrutura de financiamento onerosa em relação ao retorno que este passivos podem gerar, devendo esse custo em excesso ser coberto pelos lucros dos proprietários.

Dentro de uma configuração mais analítica proposta por Matins ${ }^{3}$ a formação do retorno do capital próprio pode ser entendida a partir de três indicadores de retorno, ou seja:

a) retorno sobre o investimento operacional $(\mathrm{ROI})$;

b) spread formado pelas decisões financeiras (ROI-ki);

c) nível de endividamento (passivo/patrimônio líquido).

Inexistindo dívidas de financiamento, o retorno do patrimônio líquido é o próprio retorno do ativo (investimento). A alavancagem ao retorno dos proprietários ocorre pela participação na estrutura de capital de fundos de terceiros captados a um custo inferior ao retorno que deles se pode obter, ou seja, quando a empresa constitui um spread favorável. Nestas condições, o risco de endividamento pode promover melhor remuneração ao investimento dos proprietários alavancando seu retorno por conta de taxas de juros passivos mais baratas.

Esta expressão mais analítica de retorno do investimento próprio, que incorpora as variáveis operacionais discutidas, apresenta-se da seguinte forma:

\section{$R S P L=R O I+(R O I-k i) \times P / P L$}

Sendo: $\mathrm{P}$ o total do passivo oneroso (passivo de financiamento) gerador de encargos financeiros, e PL, o montante do patrimônio líquido. Em outras palavras, o retorno dos proprietários é igual ao retorno gerado pelo total do investimento, acrescido de um spread determinado pelas decisões financeiras e ponderado pelo grau de endividamento.

Neste contexto de avaliação, é possível identificara origem de um efeito econômico desfavorável à empresa. Um resultado líquido negativo pode ser explicado por problemas em seu desempenho operacional, ou por uma estrutura de capital bastante endividada e onerosa. A identificação exata da origem do problema observado é, muitas vezes, a razão da predominância da empresa em seu setor de atividade. É inócua a tentativa de capitalizar uma empresa com prejuízo operacional. Em verdade, problemas no ROI devem ser solucionados através de decisões de ativos, envolvendo principalmente aspectos de giro e margem, e não de estrutura de capital.

Da mesma forma, empresas com resultado operacional positivo, porém apurando resultado líquido negativo, relevam uma estrutura de capital inadequada aos rendimentos promovidos por sua atividade.

O endividamento é alto e caro em relação ao retorno produzido pelos seus investimentos, consumindo parte da remuneração dos proprietários.

De forma esquemática, podem ser identificadas quatro possíveis estruturas de resultados nas empresas, conforma ilustradas a seguir.

\footnotetext{
${ }^{3}$ MARTINS, Eliseu. Análise da correção monetária das demonstrações financeiras. 2 ed. São Paulo: Atlas, 1984.
} 


\begin{tabular}{|lcccc|}
\hline & Estrut. A & Estrut. B & Estrut. C & Estru \\
\hline Resultado Op. & + & + & - & - \\
\hline Resultado Líq. & + & - & - & - \\
\hline
\end{tabular}

Admitindo-se como satisfatório resultado positivo, e insatisfatório negativo, as hipóteses sugeridas podem ser interpretadas consoante a natureza de seus problemas.

O desempenho da estrutura A revela uma atratividade, tanto econômica como financeira, no desempenho da empresa. A atividade objeto da empresa apresenta-se lucrativa, o que se descortina pela apuração de um resultado operacional positivo. A presença de um resultado líquido também positivo, demonstra que o endividamento da empresa não foi capaz de prejudicar seu desempenho operacional, permitindo a apuração de um lucro líquido satisfatório.

A viabilidade econômica demonstrada por uma empresa pode, ainda, ser alavancada pela presença de um custo passivo inferior ao rendimento produzido pelos ativos, que incrementa a rentabilidade dos proprietários.

O caso descrito na estrutura de resultados B revela uma empresa que não produz um retorno operacional compatível com os encargos contratados de seus passivos. Em verdade, o custo do dinheiro captado por esta empresa é elevado para os seus padrões de retorno do investimento, determinado, em razão do montante acumulado da dívida, um resultado líquido negativo.

A explicação desta situação desfavorável encontra-se fundamentalmente na decisão de estrutura de capital da empresa, em que estão as possíveis alternativas que podem ser implementadas para a retomada dos lucros. Se o desempenho operacional dos ativos estiver dentro dos padrões normais, a reversão desta posição fixa-se necessariamente na reestruturação dos passivos, avaliando-se sua maturidade, custos e natureza de seus elementos.

A empresa sugerida na estrutura $C$, ao apurar resultados (operacional e líquido) negativos, denota claramente problemas de inviabilidade econômica e financeira. Em essência, o negócio da empresa é deficitário e sua preocupação envolvendo as causas deste desempenho passa, necessariamente, pelas decisões de ativo. Devem ser consideradas, a priori, as decisões envolvendo preços, formação de custos, produtividade operacional, tecnologia, giro dos investimentos, política de estocagem, etc.

A preocupação com os passivos pode ser concomitante `a avaliação das decisões operacionais, porém a origem natural dos problemas não se localiza no endividamento. Os encargos das dividas apenas agravaram os prejuízos, não sendo responsáveis exclusivos pelas suas gerações. Tanto isto é verdade que, se a empresa viesse a substituir integralmente seus passivos onerosos por capital próprio, eliminando de modo integral suas despesas de juros, ainda assim apuraria prejuízos em razão do desempenho operacional negativo.

A estrutura $D$ reflete uma situação típica da economia brasileira em períodos de altas taxas de inflação. As empresas, de uma maneira geral, formam nestes momentos seus lucros relevantes pela geração de um ciclo de caixa superavitário. Ao realizar financeiramente suas vendas, antes dos desembolsos operacionais, produzem saldos de caixa positivos que alavancam, mediante aplicações especulativas no mercado, expressivos resultados finais.

Caderno de Estudos, São Paulo, FIPECAFI, v.16, p.9 25, julho/dezembro 1997 
A formulação analítica do retorno do proprietário permite que se avalie, ainda os impactos das estratégias financeiras formuladas por uma empresa sobre o seu valor: operacional, investimento e financiamento. A estratégia operacional é estabelecida através da relação giro versus margem, envolvendo decisões de preços, produção, estocagem, políticas de compra e de vendas, escala etc. A estratégia de investimento revela a competência da empresa em identificar alternativas que promovam um retorno superior ao custo de oportunidade do capital investido. A estratégia de financiamento avalia o custo e a estrutura de capital e o risco financeiro da empresa.

\section{O RESULTADO OPERACIONAL NO BRASIL}

Este processo analítico de avaliação das decisões financeiras tem aplicação reconhecida somente em companhias que mantém sua contabilidade ajustada aos seus objetivos gerenciais. O enunciado da legislação societária vigente sérias limitações e imperfeições para a avaliação das decisões financeiras. Ainda recentemente (1995), as empresas brasileiras ficaram legalmente desobrigadas de publicarem em seus demonstrativos contábeis pela sistemática da correção integral. Com base nesta orientação, todos os valores patrimoniais e de resultados passam a ser expressos em bases históricas, sem nenhuma forma de atualização monetária , limitando ainda mais qualquer avaliação mais acurada do desempenho econômicofinanceiro pelos de balanços.

Outros aspectos ainda poderiam ser citados reforçando a inadequabilidade dos relatórios financeiros elaborados pela legislação societária para finalidades gerenciais e decisoriais. No entanto, as observações colocadas anteriormente são irrefutáveis alertando para a fragilidade das informações contábeis legalmente apuradas para efeitos gerenciais e decisoriais.

A avaliação do desempenho operacional da empresa brasileira, identificada pelos demonstrativos contábeis publicados em correção integral das companhias de capital aberto, revelam uma reduzida capacidade de alavancagem financeira. Os negócios empresarias tem se desenvolvido, nas últimas décadas, em ambiente de elevado custo do dinheiro, situando-se, com freqüência, em percentual bem acima do retorno geralmente oferecido pelos ativos. Esta situação determinou, ao longo do tempo, um forte desestímulo econômico ao uso de capital de terceiros para financiar investimentos fixos e produtivos das empresas.

Em outras palavras, diante das elevadas taxas de juros reais praticadas em nossa economia, dificilmente pode ser identificado qualquer negócio rentável o suficiente que seja capaz de remunerar, com seus resultados operacionais, as várias fontes de capital alocadas. Historicamente, o ROI das empresas brasileiras têm-se situado ao redor da marca real de $12 \%$ ao ano, enquanto que o custo real do dinheiro praticado pelo mercado tem permanecido em níveis superiores a $20 \%$ ao ano.

$\mathrm{Na}$ verdade, não existe alavancagem financeira na economia brasileira, e as empresas vêm adotando uma postura bastante conservadora em relação, às suas decisões financeiras, priorizando a capitalização e, diante de uma postura mais lenta em relação aos investimentos, sacrificam seu poder de competitividade.

O elevado custo do dinheiro, que corta a atratividade do investimento operacional das empresas, aliado a outras causas de refluxo do capital de risco, promoveu nos últimos anos, no Brasil, uma redução de

investimentos na produção. Para ilustrar esta posição comprometedora ao desenvolvimento nacional, são demonstrados a seguir o percentual dos investimentos em relação ao PIB apurados no período 1980/91. 
Observa-se que de uma posição bastante satisfatória para os padrões brasileiros de quase $23 \%$ em 1980, a participação do investimento total caiu para cerca de 15\% em 1991. Este comportamento descendente também se verificou nos investimentos em equipamentos industriais, os quais decresceram de $8,2 \%$ para $4,1 \%$ em relação ao PIB no mesmo período.

\begin{tabular}{|lcc|}
\hline Ano & \multicolumn{2}{c|}{ Investimento Total } \\
Equipamentos & & \\
& Em relação ao PIB & em relação ao PIB \\
1980 & $22.8 \%$ & $8.2 \%$ \\
1981 & $20.9 \%$ & $6.7 \%$ \\
1982 & $19.4 \%$ & $5.6 \%$ \\
1983 & $16.8 \%$ & $4.6 \%$ \\
1984 & $16.2 \%$ & $4.7 \%$ \\
1985 & $16.3 \%$ & $4.9 \%$ \\
1986 & $18.6 \%$ & $5.9 \%$ \\
1987 & $17.8 \%$ & $5.4 \%$ \\
1988 & $17.0 \%$ & $4.9 \%$ \\
1989 & $16.6 \%$ & $4.7 \%$ \\
1990 & $16.0 \%$ & $4.4 \%$ \\
1991 & $15.2 \%$ & $4.1 \%$ \\
\hline
\end{tabular}

Como conseqüência natural, muitos setores de atividade passaram a priorizar a capitalização, colocando a empresa brasileira com um indicador de endividamento médio dos mais baixos do mundo. Foi sacrificado o giro dos recursos próprios e, também, a própria capacidade de investir, em troca de uma política mais preocupada com a sobrevivência financeira da empresa.

Nos anos 90, o índice médio de endividamento das companhias de capital aberto no Brasil vem registrando a marca de 0,50 , o que eqüivale a um ativo total financiado em $67 \%$ por capital próprio e $33 \%$ por recursos de terceiros. Padrões de endividamento em economias mais desenvolvidas, como Japão e EUA, elevam este índice para 1,50, marca três vezes superior que a atingida por nossas empresas.

Esta situação, é evidente, enfraquece o poder de competitividade da empresa nacional, permitindo questionar inclusive a efetiva capacidade de continuidade de alguns empreendimentos em ambiente de maior abertura econômica. Formação de preços, desenvolvimento e qualidade dos produtos são, em essência, as variáveis estratégias mais atingidas, limitando bastante a capacidade da empresa em atuar em mercados mais competitivos e globais.

É importante que se registre, ainda, que esta marca de segurança estabelecida pela maior presença de capital próprio na empresa, não se origina sempre do mérito de uma gestão mais eficiente dos negócios, principalmente em termos de geração de lucros e reinvestimentos.

Em verdade, a capitalização da empresa brasileira é mais uma questão de respeito ao princípio da sobrevivência pois não é normal deparar-se com algum negócio com fôlego de remunerar, pelo menos, às taxas de juros que se estabeleceram no país nos últimos tempos. 


\section{INTERDEPENDÊNCIA FINANCEIRA E EQUILÍBRIO}

O esquema básico das decisões financeiras, conforme comentado, envolve o volume selecionado de investimento e o montante e natureza das fontes de financiamento. Neste contexto, as decisões empresariais devem levar em conta, também, a interdependência dos fluxos de caixa resultantes, de maneira a contribuir à formação do equilíbrio financeiro da empresa.

Em condições de estabilidade financeira, as decisões de investimento devem promover um retorno (geração) de caixa compatível com o fluxo de desembolsos demandado pelas fontes financiadoras. Em outras palavras, captações de passivo devem idealmente ser reembolsadas com os resultados de caixa promovidos pelos ativos financiados, de maneira que se viabilize financeiramente a decisão de investimento.

No Brasil, as decisões de financiamento, nas condições ideais de equilíbrio, são bastante prejudicadas pela insuficiente disponibilidade de recursos a longo prazo para as empresas. Basicamente, os recursos oficiais são as grandes fontes de capital permanente e, mesmo assim, em volume bastante aquém das efetivas necessidades de mercado.

O sistema BNDES, principal lastro financeiro do crescimento das empresas brasileiras, convive com um orçamento bastante limitado face às efetivas necessidades de investimento da economia. Suas linhas de crédito de longo prazo, além de incapazes de atender plenamente a demanda por crédito, são geralmente direcionadas a programas específicos, atendendo a um número reduzido de empresas.

Neste contexto, a ausência de um mercado de capitais mais evoluído promove uma séria restrição de recursos de longo prazo necessários ao financiamento de investimentos de capital no Brasil, limitando a capacidade de crescimento e competitividade das empresas.

As bolsas de valores brasileiras, por seu lado, não se mostram economicamente competentes para suprir as empresas do volume necessário de capital permanente para financiar seu crescimento. São de tamanho ainda reduzido e conseguem manter a liquidez de somente uma pequena quantidade de ações.

É importante avaliar também o forte predomínio da cultura familiar nas empresas brasileiras. De acordo com estudos efetuados por Bethlem ${ }^{4}$, algo em torno de $60 \%$ dos grandes grupos empresariais nacionais são de propriedade de um indivíduo. De maneira mais ampla, 90\% de nossas empresas pertencem a um indivíduo ou a um grupo bastante reduzido de pessoas.

Este forte predomínio familiar na atividade produtiva, segundo o mesmo estudo, teme a perda do controle de capital da empresa. A procura pela manutenção do controle acionário, dependendo da intensidade que se processa, pode levar ao sacrifício do crescimento e da própria capacidade de continuidade dos negócios. A empresa afasta-se do mercado de capitais para não dividir o poder decisório com outros investidores, tornando-se, por outro lado, vulnerável ao atuar em ambiente de maior competitividade.

Não existindo o controle acionário disponível no mercado, a questão essencial é interpretar o efetivo significado do valor de uma ação. A sua cotação deve refletir o valor do mercado do patrimônio líquido da empresa, incorporando todos os ativos, líquidos das exigibilidades, e acrescido de um eventual goodwill

\footnotetext{
${ }^{4}$ BETHLEM, a Características da empresa e do ambiente brasileiro. São Paulo, FGV, Revista de Administração de Empresas, 35 (01), jan/fev., 1995.
}

Caderno de Estudos, São Paulo, FIPECAFI, v.16, p.9 25, julho/dezembro 1997 
formado pela sua capacidade de gerar resultados superiores aos padrões tidos como normais. Não refletindo o efetivo valor da empresa face a um desempenho esperado.

Pelas limitações de acesso ao crédito externo, as empresas brasileiras tem procurado financiar seu crescimento através de recursos gerados pelas suas próprias operações. No entanto, o montante disponível desta origem não é suficiente para lastrear as necessidades crescentes de recursos, notadamente diante da maior competitividade do mercado que vem exigindo maiores investimentos em pesquisa e desenvolvimento de produtos.

Nestas condições de carência de recursos de maior "maturidade", o endividamento da empresa brasileira vem se concentrado a curto prazo, limitando a folga financeira e sua capacidade de expansão em equilíbrio. Na convivência com esta estrutura financeira, as decisões empresariais reiteram a preferência pela capitalização, privilegiando a sobrevivência financeira das empresa. $O$ financiamento a longo prazo passa a depender, ainda segundo Bethlem, de maneira mais relevante, do alto prestígio da empresa no mercado - ao promover colocações bem sucedidas de ações e debêntures - e de operações de fusões, aquisições e incorporações, que permitem promover o crescimento das empresas sem necessidade de se posicionarem de forma mais dependente do mercado de capitais.

Se, por um lado, fusões e aquisições justificam-se como forma de promover a busca de qualidade e redução dos custos, de outro lado, este processo, da forma como vem sendo conduzido no Brasil tem proporcionado uma crescente concentração de empresas, cujos índices são significativamente superiores aos de outros países.

Um estudo bastante abrangente, desenvolvido pelo IPEA ${ }^{5}$, revela que 17 (dezessete) setores relevantes da economia nacional apresentam um índice médio de concentração de mercado três vezes maior que o considerado altamente preocupante nos EUA. O poder dos oligopólios no Brasil ainda é bastante elevado, principalmente na área de formação de preços. O referido estudo do IPEA pesquisou que oligopólios da área de alimentos, higiene e limpeza, por exemplo, suspendem suas vendas assim que atingem a cota de comercialização estabelecida para o período. Com esta decisão, evitam que os preços de seus produtos recuem por eventual excesso de oferta.

A abertura de mercado da economia brasileira para a concorrência estrangeira vem sendo conduzida de maneira lenta, permitindo a livre atuação destes oligopólios em diversos setores de atividade. Na empresa nacional, ainda é comum encontrar raízes das idéias de protecionismo entre os empresários, os quais costumam aguardar, muitas vezes motivados pelos desequilíbrios estruturais de nossa economia, a participação financeira do Estado em seus empreendimentos. O protecionismo cria uma reserva de mercado para vários produtos e serviços, atuando como um forte limitador da busca por custos menores e maior qualidade.

O OBJETIVO DA EMPRESA E O DIMENSIONAMENTO DE SEU VALOR

As finanças das empresas, em seu estágio inicial consideradas como parte do estudo da Economia, vem descrevendo ao longo do tempo um processo consistente de evolução conceitual e técnica. A partir dos

\footnotetext{
${ }^{5}$ Publicado no Jornal Folha de São Paulo em 28.08.94.
} 
anos 20, já entendida como uma área independente de estudo, as finanças empresariais são motivadas a evoluírem de maneira a atenderem a crescente complexidade assumida pelos negócios e pelas operações de mercado. Nos dias atuais, a área financeira passou de uma postura mais conservadora e de absoluta aceitação dos fatos, para uma posição bem mais questionadora e reveladora dos fenômenos financeiros. É fundamental, no contexto moderno, a identificação e entendimento das causas de determinado comportamento, e não somente a mensuração dos valores registrados e dos efeitos produzidos pelos fatos financeiros.

Até a década de 20, as Finanças passaram a enfatizar mais os instrumentos e procedimentos do mercado de capitais voltados à captação de recursos. A preocupação essencial das empresas, entendida pela Administração Financeira, fixava-se nas fontes externas de recursos, representadas por banqueiros, acionistas e poupadores.

A partir deste período, impulsionada pelas novas teorias administrativas desenvolvidas por Taylor e Fayol, as finanças das empresas passaram a se voltar para os aspectos internos da empresa, ao aperfeiçoamento de suas tarefas e procedimentos, e desenvolvimento de sua estrutura organizacional. Este enfoque, de caráter mais administrativo, foi reforçado com a depressão econômica em 1929/30, tornando o estudo das finanças também preocupado com a liquidez e solvência das empresas.

$\mathrm{Na}$ década de 40 e até meados dos anos 50, as Finanças voltaram a enfocar as empresa a partir de decisões externas, estudando-as sob o ponto de vista de um emprestador de recursos ou aplicador, sem atribuir maior destaque às decisões internas.

$\mathrm{Na}$ metade da década de 50, contudo, foi dada ênfase destacada aos investimentos empresariais e geração de riqueza. A Administração Financeira preocupava-se tanto com a alocação eficiente dos recursos como com a seleção adequada de suas fontes de financiamento. Dois importantes conceitos financeiros foram desenvolvidos neste ambiente: retorno do investimento e custo do capital, destacando a interdependência das decisões financeiras, conforme amplamente discutida em itens anteriores.

Esta abordagem mais contemporânea das Finanças prioriza sua atenção nas decisões de investimento, financiamento e dividendos, de maneira a promover a riqueza de seus acionistas, minimizando os riscos e tornando mais eficaz os recursos alocados. Fundamentalmente, a Administração Financeira está voltada para a criação de riqueza, e a orientação básica das decisões financeiras das empresas segue o objetivo principal de maximização da riqueza de seus proprietários. Ao perseguirem este objetivo, as decisões financeiras beneficiam não somente os investidores da empresa, mas permitem, ainda, que se reflita nos recursos econômicos da sociedade, maximizando a riqueza de toda a economia.

Este objetivo das finanças das empresas é mensurado pelo valor que suas ações ordinárias alcançam no mercado, refletindo, em última análise, as expectativas dos acionistas com relação aos resultados das decisões financeiras tomadas. Os investidores de ações reagem à baixa qualidade das decisões financeiras, desvalorizando o valor de mercado das ações, promovendo, ao contrário, valorizações como conseqüência de melhores decisões. Em outras palavras, a qualidade das decisões de investimento e financiamento é que efetivamente determina a riqueza dos proprietários.

Nesta evolução das finanças das empresas, que desemboca no objetivo de maximização da riqueza de seus proprietários, evidencia-se uma preocupação na forma como a empresa é avaliada e no impacto que cada decisão financeira determina sobre a riqueza.

Caderno de Estudos, São Paulo, FIPECAFI, v.16, p.9 25, julho/dezembro 1997 
Inúmeros modelos de avaliação foram desenvolvidos para serem utilizados no processo de tomada de decisões financeiras. Neste contexto, destaca-se inicialmente o trabalho publicado em 1958 por Modigliani \& Miller, que aborda, conforme descrito anteriormente de maneira bastante inovadora, a relação da estrutura de capital e política de dividendos com o valor da empresa. As discussões destas idéias se estendem até os dias atuais, principalmente relacionadas aos pressupostos assumidos na existência de um mercado de capitais perfeito, e às características discutidas da economia brasileira.

A partir dos anos 50 e 60, começou a se desenvolver a Teoria do Portfólio, inicialmente apresentada por Markowitz ${ }^{6}$ e estendida por Fama; Sharpe; Linter ${ }^{7}$, entre outros importantes trabalhos. Esta teoria em essência, expõe que o risco de um ativo deve ser avaliado a partir de sua contribuição ao risco total de um portfólio de ativos, e não de maneira isolada.

O risco de um ativo individual somente é relevante para o investidor que possua somente este ativo. No caso do investidor com vários ativos, o risco de um título é avaliado com base em sua contribuição ao risco da carteira. Dependendo ainda do grau de correlação do ativo com o portfólio, este apresentará um nível maior ou menor de risco. Desta maneira, pode-se concluir que o risco de um portfólio depende não somente do risco de cada ativo que o compõe, mas também da relação existente entre esses ativos.

Um aspecto essencial desta colocação é a idéia de que o risco de qualquer ativo mantido em uma carteira não deve coincidir com seu risco individual avaliado fora do contexto da carteira. $O$ impacto que o risco de um ativo promove sobre o risco de toda carteira é demonstrada pela Teoria da Diversificação.

O modelo do portfólio sugere também que parte do risco de um ativo pode ser eliminado pela diversificação, não sendo relevante ao investidor em suas decisões. O risco efetivamente relevante do investimento é o denominado risco satisfatório, sobre o qual o investidor não tem poder de controle. Este risco, caracterizado como inevitável, afeta com diferentes intensidades a todos os elementos que compõe o portfólio, e é específico `a natureza da atividade do ativo, não sendo possível sua eliminação pela diversificação.

Esta teoria predominante da Administração Financeira orienta que um investimento deve ser avaliado pela sua contribuição aos resultados de risco e de retorno produzidos por uma ampla (diversificada) carteira de ativos. Não deve ser predominar entre os aplicadores de capital uma maior preocupação com o desempenho isolado de um ativo, mas com o reflexo que determinada decisão financeira promove sobre todo o portfólio.

Outros modelos teóricos surgiram posteriormente, promovendo importantes contribuições ao estudo da avaliação de empresas. Nesta linha citam-se, entre outros, a APT - Arbitrage Pricing Model e o modelo de opções de Black e Sholes ${ }^{8}$. No entanto, as evidentes imperfeições do mercado de capitais e limitações das informações financeiras acessíveis têm prejudicado, em muito, a aplicação mais generalizada destes modelos de avaliação em nossa economia.

É observado, com certa freqüência, o uso de balanços patrimoniais para se estabelecer o valor da empresa, ou comparar certos valores definidos para negociações de mercado. Em verdade, a informação

\footnotetext{
${ }^{6}$ MARKOWITZ, Harry M. Portfólio selection. John Willey, 1959.

${ }^{7}$ Ver FAMA, Eugene F. \& MILLER, Merton M. The theory of finance . s/l: Holt, 1992; SHARPE, William F. Capital asset prices: a theory of market equilibrium under conditions of risk. Journal of Finance, sept. 1964; LINTER, John. Security prices, risk and maximal gains from diversification. Journal of Finance, 1965.

${ }^{8}$ Ver ROSS, Stephen A. The arbitrage theory of capital asset pricing. Journal of Economic Theory, dec. 1976; BLACK, Fischer \& SCHOLES Myron. The pricing of options and corporate liabilites. Journal of political Economy, may-jun, 1973.
}

Caderno de Estudos, São Paulo, FIPECAFI, v.16, p.9 25, julho/dezembro 1997 
contábil, tal como é apurada de modo convencional, não reflete o valor de mercado de um ativo. A Contabilidade costuma expressar seus valores com base no princípio do custo, que está preferencialmente voltado para a apuração do lucro, e não para expressar os valores de venda dos ativos.

Assim, o montante do patrimônio líquido ou valor patrimonial da ação, medidas contábeis com freqüência sugeridas em avaliações de investimento, nada tem a ver com o valor de mercado da requerida de retorno determinada para a alocação de capital. Este é um critério básico de aceitação de propostas de investimentos, o qual leva ao incremento do valor de mercado da empresa.

As informações que compõem o contexto da avaliação das decisões de investimento (fluxos de caixa e taxa de atratividade) são dimensionadas de forma incremental. Isto é, relevante para o investimento são os valores originados da própria proposta, estando associados ao capital dispendido. Valores que venham a se manter inalterados diante das propostas de investimentos devem ser desconsiderados da avaliação, uma vez que não exercem influência sobre a gestão.

Em consonância com o objetivo estabelecido para a empresa, a aceitação de uma proposta de investimento deve-se voltar à maximização da riqueza dos proprietários de capital. Nesta posição, para cada investimento deve ser comparado o desempenho econômico esperado da proposta em avaliação com a taxa de retorno exigida pelos proprietários e enunciadas pelo mercado.

A atratividade de um investimento é função das características de risco e retorno inerentes ao projeto, e não da empresa como um todo. Em verdade, a rentabilidade requerida altera-se diante das características do projeto, em termos de risco, retorno e estrutura dos fluxos de caixa.

Ainda de acordo com a Teoria de Finanças, a avaliação de propostas de investimento é desenvolvida a partir de fluxos de caixa operacionais, formados, exclusivamente, pelas decisões de ativos. Conforme foi amplamente discutido, a atratividade de um ativo não pode vincular-se à forma como ele se encontra financiado, e sim pela qualidade de seus resultados operacionais esperados.

A introdução deste modelo conceitual de avaliação de investimentos no ambiente empresarial brasileiro apresenta algumas importantes restrições, principalmente ditadas pela não homogeneidade das taxas de juros de mercado. Mesmo em situação de reduzida taxa de inflação, a economia vem convivendo com taxas de juros de mercado superdimensionadas, principalmente em relação ao retorno padrão produzido pelos ativos das empresas, em torno de $12 \%$ ao ano.

A reação observada nas empresas brasili diante desta realidade, conforme comentado, foi pitalização. Nos dias de hoje, a empresa nacional a senta um dos mais baixos índices de endividam do mundo, posição esta alcançada, é importante que se registre, não pelo mérito ou livre escolha de administração, mas como um recursos para manter-se viável no tempo. Exceto o segmento dos limitados cursos oficiais de crédito, cujos custos subsidiados eram condizentes com a capacidade de retorno destes fundos, as taxas de juros livremente praticadas no mercado vêm se situando bem acima do retorno dos ativos inviabilizando a participação do capital de terceiros maior parte das propostas de investimentos.

Nesta condição, é possível constatar-se que a empresa que tenha financiado seu crescimento, a partir dos anos 80 , com recursos de terceiros captados a taxas de mercado, dificilmente se mantém em termos de equilíbrio financeiro idônea nesta década constatável que, as de maior "fôlego" financeiro, e que portanto, conseguiram "bancar" esta posição deficitária, atingiram em determinado momento o limite de sua 
capacidade financeira, promovendo um profundo acesso de reengenharia de seus passivos. Outras, de menor capacidade de sobrevivência financeira, tendem a desaparecer do mercado.

As demais, que lograram competir no mundo, com predominância de passivos oficiais, lastrearam seu crescimento com recursos subsidiados em relação às taxas livremente praticadas no mercado. A qualidade destes investimentos é que definirá sua capacidade de se manter em um ambiente de competição com taxas de juros mais homogêneas e mercado mais exigente.

Uma observação bastante indicativa, já discutida sobre este desequilíbrio de mercado são os valores bastante diferenciados assumidos pelas taxa juros, sendo definidos, pela natureza do financiam (recursos oficiais, privados, externos etc.) e não, como deveria de se esperar, pelo risco associado à opção.

Muitas vezes, ainda, em operações pós-fixadas, o indexador utilizado vem se mantendo distante da efetiva taxa de inflação da economia proporcionando,um custo adicional à empresa. Este tipo de financiamento pós-fixado tem revelado que a escolha do fator de indexação do principal torna-se tão relevante (algumas vezes até mais importante) quanto a taxa de juro cobrada e as demais condições financeiras do crédito. A estrutura de capital da empresa e, em consequência, o seu custo de capital e risco financeiro, podem se alterar diante da presença de múltiplos indexadores em sua estrutura de passivos. Mesmo que qualquer decisão de amortização de a estrutura de capital pode se alterar diante de desiguais comportamentos dos indexadores do passivo.

Desta maneira, é relevante na teoria das decisões financeiras, refletir-se sobre a interferência das decisões de financiamento sobre a avaliação de investimentos. Em verdade, em certas situações, um projeto de investimento, em princípio pouco atraente, pode viabilizar-se se financiado; por exemplo, com recursos disponíveis na economia. Isto é uma realidade presente em nossa economia.que precisa, de alguma forma, ser incorporada ao estudo das decisões de investimento.

\section{Conclusões}

A Teoria de Finanças vem evoluindo em bases conceituais bastante coerentes e estruturadas, permitindo dar um escôpo mais consistente à Administração Financeira. Em termos técnicos, inclusive, os modelos financeiros de avaliação têm-se sofisticado incorporando propostas bastante avançadas e criativas.

As decisões financeiras estão calçadas em diversos pressupostos, que dão toda sustentação aos seus enunciados e modelos. Observa-se grandes preocupações em discutir o relaxamento destes pressupostos, e seus reflexos práticos sobre a Administração Financeira. É considerável o avanço que vem sendo feito neste sentido, permitindo uma maior proximidade entre a teoria financeira e a realidade do mercado e das empresas.

Todavia, a preocupação com economia em processo de desenvolvimento, cujas características básicas são, em grande parte, bastante semelhantes entre si, ainda não tem merecido idêntica atenção. A Teoria de Finanças discutida incorpora seus pressupostos originais sem atribuir maior preocupação a desequilíbrios estruturais de mercado tão comuns em países em desenvolvimento. Taxa de juros subsidiadas, taxas de curto prazo mais elevadas que as de longo prazo, elevado grau de concentração industrial, conjuntura com 
frequentes intervenções do estado, entre outros, constituem-se na realidade destas economias, direcionando o conjunto das decisões financeiras para um contexto de variáveis diferenciadas e de forte influência sobre os resultados. Efetivamente, não é somente a inflação que altera a consistência original da teoria financeira. Os aspectos, relatados de maneira sucinta, encontram-se presentes mesmo em economias com taxas de inflação relativamente sob controle.

É uma situação de desequilíbrio das regras de mercado, a qual requer, para o desenvolvimento das empresas e da própria aplicação prática da Teoria de Finanças, uma maior atenção na elaboração de modelos identificados com esta realidade.

Pela teoria de MM (Modigliani-Miller), é irrelevante para o objetivo de maximização da riqueza debaterse como a empresa deve financiar-se: se por aumento de capital próprio ou por endividamento. $\mathrm{O}$ valor de mercado da empresa não se altera, independente de como ela se financia.

A descontinuidade discutida do custo de capital de terceiros, por outro lado, promove alterações relevantes na estrutura de capital da empresa e, em conseqüência, em seu risco financeiro. Com isto, a atratividade econômica de um investimento pode ser alterada em função da natureza das fontes de recursos que o financiam.

As decisões financeiras das empresas não são definidas a partir dos pressupostos de uma ciência exata, em que se permite a comprovação absoluta dos resultados. Os fatores considerados na tomada das decisões procuram retratar a realidade do ambiente econômico, estando ainda calcadas em certas premissas e hipóteses comportamentais. Todo modelo decisorial, por exemplo, desenvolve expectativas para a fixação dos resultados esperados, do período de previsão, e da definição da taxa de atratividade econômica do empreendimento.

Por melhor quantificados que sejam, estes parâmetros previstos constituem-se em aproximações bastante razoáveis da realidade, incorporando, como é natural projeções e certa margem de arbítrio trazida pela unidade decisória. Não há uma fórmula inquestionável para as decisões financeiras. É exigido o domínio dos conceitos teóricos financeiros, de suas técnicas e procedimentos e dos inúmeros fatores que condicionam o desempenho e o valor da empresa.

Uma empresa somente cria valor se o retorno do capital investido exceder ao custo de suas fontes de financiamento. Ao tomar decisões de investimento que proporcionam esse diferencial economicamente favorável, a empresa promove um aumento de seu valor agregado, revelando uma atraente aplicação de seus recursos.

A avaliação de uma empresa para a Teoria de Finanças volta-se, essencialmente, ao seu valor intrínseco, o qual é função dos benefícios econômicos de caixa esperados, do risco associado a esses resultados previstos, e da taxa de retorno requerida pelos investidores. São esses parâmetros decisórios básicos, definidos pelas expectativas dos investidores com relação ao desempenho esperado e de seu grau de aversão ao risco, que determinam o valor de mercado de uma empresa.

Apesar das limitações e dificuldades inerentes à interdependência financeira das decisões empresariais, muitas empresas vêm se desenvolvendo, transpondo dificuldades e barreiras impostas por um mercado financeiro desajustado ao equilíbrio das empresas. Alguns setores, no entanto, principalmente aqueles que atuam em mercado de maior competitividade, ressentem da falta de recursos maior 
"maturidade", de forma a viabilizar seus investimentos do ponto de vista financeiro e gerar maior capacidade de concorrer com outras empresas.

$\underline{\text { Resumo }}$

O artigo propôs uma maior reflexão sobre a Teoria das Finanças das empresas e sua adequação a empresas inseridas em economias emergentes. As características diferenciadoras deste contexto econômico exigem ajustes nos enunciados financeiros, de forma a viabilizar as aplicações das técnicas financeiras.

O artigo desenvolveu, ainda, uma avaliação das decisões financeiras e sua interdependêcia ressaltando a apuração dos resultados operacionais. Tratou, também, a evolução da Teoria de Finanças cobrindo os anos 20 até os tempos atuais. Neste horizonte de mudanças, as Finanças empresariais ganharam maior estrutura conceitual e de avaliação de risco, preparando-se para atender à crescente complexidade dos negócios e das operações de mercado.

Interessantes conclusões foram extraídas do estudo, ressaltando-se a importância do conhecimento da Teoria de Administração Financeira para um melhor entendimento do mercado e do processo decisório das empresas.

$\underline{\text { Referências Bibliográficas }}$

ASSAF NETO, Alexandre \& MARTINS, Eliseu. Administração financeira. SãoPaulo:Atlas, 1987.

BETHLEM, A.. Características da empresa e do ambiente brasileiro. São Paulo, Fundação Getúlio Vargas, Revista de Administração de Empresas, 35(01), jan./fev., 1995.

BLACK, Fisher \& SCHOLES, Myron. The pricing of options and corporate liabilities. Journal of Polítical Economy,may/jun, 1973.

FAMA, Eugene F. \& MILLER, Merton M.. The theory of finance.s/l: Holt, 1992.

Folha de São Paulo. Índice de concentração Industrial. 28.08.94.

LINTER, John. Security prices, risk and maximal gains from diversification..Journal of Finance, 1965.

LUENBERGER, David G.. Investment science. NewYork: Oxford University Press, 1998.

MODIGLIANI, Franco\& MILLER, Merton H.. The cost of capital corporate finance and the theory of investment. American Economic Review, jun., 1958. 
MARTINS, Eliseu. Análise da correção monetária das demonstrações financeiras. São Paulo: Atlas, 1984.

MARKOWITZ, Harry M. Portfolio selection. s/l: John Wiley, 1959.

ROSS, Stephen A. The arbitrage theory of capital asset pricing. Journal of Economic Theory, dec.1976.

SHARPE, William F. Capital asset prices: a theory of market equilibrium under conditions of risk. Journal of Finance, sep., 1964.

VAN HORNE, James C. Financial management and policy. 10.ed.. Prentice Hall International, Inc, 1995. 